Drug and Alcohol Review (January 2015), 34, 27-30

DOI: $10.1111 /$ dar. 12219

\title{
COMMENTARY
}

\section{Punishing parents: Child removal in the context of drug use}

\author{
ANNA OLSEN \\ The Kirby Institute, University of New South Wales, Sydney, Australia
}

\begin{abstract}
New amendments to child welfare policy in New South Wales turn a spotlight on parents who use drugs and raise concerns about adequate provision of services for families facing issues with alcohol and other drug use. Sections of the new legislation are explicitly focused on parents who use illicit drugs, expanding the reach of child protection services over expectant parents during pregnancy. This targeting of women who are 'addicted' highlights the ambiguous scientific and moral attention to drug use in pregnancy. It also raises practical questions about the potential for the legislation to increase stigma towards drug use and disproportionately affect vulnerable and disadvantaged families. [Olsen A. Punishing parents: Child removal in the context of drug use. Drug Alcohol Rev 2015;34:27-30]
\end{abstract}

Key words: parenting, motherhood, drug use, child removal, child protection.

Introduced by Family and Community Services Minister, Pru Goward, the Child Protection Legislation Amendment Act 2014 (passed in March this year) makes a number of amendments to the Children and Young Persons (Care and Protection) Act 1998, including: expansion of Parental Responsibility Contracts to include expectant mothers; court-issued Parental Capacity Orders; and a streamlining of open adoption. Under the new legislation the Department of Community Services can apply to the Children's Court to enter into parental responsibility contracts with parents, or expectant parents, where the child or foetus is considered at risk of neglect. The contracts require parents to undertake a course of action, such as attending a parenting program or refraining from using illegal drugs. Parents who refuse to enter into a contract or breach a contract would risk having their children removed, including at birth, on protection grounds. New South Wales (NSW) already has the highest rate of child protection notifications in Australia (61\% of national notifications) and the highest level of child protection activity [1]. Furthermore, prior to these changes, NSW already had in place a policy of mandatory reporting whereby health professionals and those employed in welfare, education, children's services, residential care and law enforcement are legally obliged to report to Child Services if they believe that a child, or unborn foetus, is at risk of harm.
Given the already high levels of reporting in the state, alongside pre-existing laws in place to notify services of suspected endangerment of children and foetuses, the move to coercive regulation of expectant parents requires scrutiny. In particular, the fact that 'addicted mums' are a key focus of the new legislation; 'Under these new laws', says Pru Goward, 'if an expectant mother with a drug addiction doesn't fulfil their obligations the government will take steps to protect the child' [2]. This targeting of women who are 'addicted' highlights the ambiguous scientific and moral attention to drug use in pregnancy. It also raises practical questions about the potential for the legislation to increase stigma towards drug use and disproportionately affect vulnerable and disadvantaged families.

Parental drug use, as a precipitating cause of child removal, features frequently in the literature and in practice $[3,4]$. Parental alcohol and other drug use is associated with child protection notifications [5] and estimates suggest that $50-80 \%$ of parents who have contact with child protection services have a history of alcohol and other drug use [6]. But what categorises problematic or risky alcohol and other drug use? There is no universal agreement about the meaning of 'drug' or 'addiction' in the context of impaired or abusive parental capacity [3]. Despite the clinical evidence for foetal alcohol spectrum disorder and neonatal abstinence syndrome, the biological, environmental and 
behavioural processes involved in causing these disorders are rarely straight forward and regularly contested. For example, advice given to pregnant women varies about whether or how much alcohol they should drink. Because a lower limit of safe alcohol exposure has not been established, several countries, including Australia, advise pregnant women to abstain from alcohol completely [7]. Based on the lack of evidence for harm with low levels of alcohol consumption, however, there have been calls to reconsider Australia's guidelines to a more levelled harm reduction approach to alcohol in pregnancy [8]. The debates surrounding illicit drug use in pregnancy are similarly controversial, if not more so.

There is a plethora of substances that women are instructed to refrain from during pregnancy, from soft cheeses to certain medicines; however, the consumption of only some substances appear to warrant strict intervention or punishment. Tobacco use is known to be harmful in pregnancy and approaches to reduction/ cessation generally include cognitive behaviour and motivational interviewing, incentives and nicotine replacement therapy [9]. Punitive measures, such as child removal, are not employed. When it comes to illicit drug use during pregnancy, any quantity of consumption is readily conflated with abuse, harm and lack of control. Informed by the social construction of 'crack babies' and 'junkie mums', bolstered by neoliberal public health theories about lifestyle 'choice' and selfpolicing, women (more than men who take drugs) are popularly constructed as disgraced parents, encouraged not to have children $[10,11]$ and targeted for surveillance within public policies and programs.

The NSW Child Protection Legislation Amendment Bill also raises legal issues, in particular the expansion of legislation dealing with unborn children (i.e. foetuses). Although the original legislation contains a section on prenatal reporting to child welfare services (Section 25), new amendments extend the parameters of state influence on pregnant women. The law does not limit what can be included in a Parental Responsibility Contract, and expectant parents may be required to adhere to set regimens and outcomes, such as drug treatment and abstinence. If a Parental Responsibility Contract is deemed to be breached the case may be referred to the Children's Court where the expectant parents must prove that the foetus is not in need of care and protection. For civil libertarians, feminists, abortion rights and harm reduction advocates such provision for state regulation of a pregnant woman represents a punitive response to the issue of prenatal drug use and poses a threat to women's rights and bodily sovereignty [12].

Intended to represent the rights of the foetus, often over the rights of the mother, or parents, there has been much debate over laws that afford legal 'personhood' to foetuses. In the USA, legislative battles over personhood have led to the creation of offences against pregnant women and states, such as Tennessee, have enacted laws that allow criminal charges to be brought against pregnant women who use drugs. These laws 'hold women liable for prenatal conduct that may (or may not) cause harm to the foetus' based on the notion that the foetus is a separate person, possessing rights that conflict with those of the mother [13]. Although the NSW Child Protection Legislation Amendment Bill does not legally provide status of personhood to the foetus, extending parental contracts to unborn children sits precariously close to holding women solely accountable for the 'person' inside them. Simultaneously in NSW the Crimes Amendment (Zoe's Law) Bill 2013 has been introduced into NSW parliament in which the definition of 'unborn child' would be redefined to 'person' under NSW criminal law. The ensuing debate among lawyers and advocates highlights concerns about the potential for the legislation to endanger contemporary laws that protect reproductive rights.

Regulations, such as Parental Responsibility Contracts, assume that women who use drugs are in an adversarial relationship with the foetus [13]. However, in-depth investigations of women's lives illustrate the efforts they go to in order to reduce the impacts of their drug use on their children $[14,15]$. Women who enter drug treatment often do so for child-related reasons and attempt to shield their children from their drug use [16]. Many women who use illicit drugs fear their children being taken into care and report feeling stigma, alienation and fear of consequences when in contact with social and health services $[17,18]$. In fact, contemporary research from NSW reveals the exposure risk for families who actively engage in social and health services. With approximately one-third of child welfare reports against drug using women occurring via health services (opioid treatment program, hospital or other medical service) [19], even those women adhering to state expectations by entering drug treatment are more likely to come into contact with child welfare services. The social stigma surrounding drug use is often enough to disguise these 'unequal impacts of public health policies and interventions across the population' [20].

Instead of constraining pregnant women and using child removal as threat against compliance, Australian laws should reflect the national and international guidelines for management of substance use in pregnancy that include: ensuring access to prevention and treatment services; respecting patient autonomy; continuity of care; and safeguarding against discrimination and stigmatisation $[21,22]$. The guidelines emphasise the importance of establishing a sound therapeutic relationship with parents based on respect and nonjudgmental attitudes. Incentivised engagement in drug 
treatment and antenatal care is supported; however, recommendations focus on a carrot rather than a stick approach. Contingency management (the provision of vouchers, cash or other incentives) has been found to be effective in engaging pregnant women in consistent and continuous care [21].

According to the new legislation, Parental Responsibility Contracts are primarily aimed at improving parenting skills and reducing the likelihood that the child will be at risk of significant harm (Section 38A) [23]. The NSW Government states that these new laws will be underpinned by an additional $\$ 35$ million in funding, including the provision of early intervention services. Indeed, the 2014-2015 state budget estimates show a commitment to several targeted interventions for vulnerable children, young people and families [24]. Still, almost $\$ 200$ million more is to be spent on statutory child protection than early intervention. Opponents to the new Child Protection amendments are concerned about the availability and accessibility of services and the potential for these laws to unequally impact on poorer families. Punitive responses to health issues, such as drug use in pregnancy, often occur without critical consideration of the broader social, economic and political dimensions of health. If parents are expected to adhere to directives under Parental Responsibility Contracts, their ability to do so must not be hampered by inadequate service availability and access. For instance, there is a major shortage of opioid substitution prescribers in Australia [25] resulting in long waits to commence treatment and issues with continuity of treatment [26].

Research shows that child maltreatment is not associated specifically with 'parental drug use as a single risk factor, but rather with the complex interplay between drug use, maternal psychopathology, parenting practices, family environment (including spousal relationship and the availability of social support), and socioeconomic factors such as unemployment and poverty' [27]. Most social problems 'cross the bounds of several specialist areas of policy and practice, and no single discipline possesses the knowledge required to manage the multiple facets of families with complex issues' [28]. Parents who use drugs and/or experience poverty may have different experiences and expectations of pregnancy and child-rearing to state institutions as well as other needs outside of their reproductive health. Parents must have a say in what is achievable and realistic when entering into a contract agreement with the state, including services that are culturally, financially and geographically suitable for that family [29].

Consumer involvement in research and policy to understand risk perceptions and management from the perspective of parents could better inform interventions
[30]. Services research on consumer experience and outcomes provides evidence for the integration of family programs and drug treatment. Supporting parents through the provision of services beyond drug treatment, such as child care, education and transportation, can improve engagement and outcomes [31]. Yet without social services policy, fiscal and structural support, it is difficult to establish interventions that address multiple domains of family well-being, including drug use, parenting skills, support networks, housing, medical and child-care services.

The recent policy agenda in NSW has reignited the conversation on 'dangerous mothers' and raises questions about Australia's policy approaches to women who use drugs, pregnancy and family. Although legal and illegal drugs can pose negative consequences for expectant parents or their children, ultimately this is a social issue, not a criminal one. Legislation such as the expansion of Parental Responsibility Contracts and the unabashed targeting of women who use illicit drugs are legitimised by a shared social desire to improve the health of children. However, at the same time, it must be recognised that such programs institutionalise stigma against women who use drugs and may in fact reproduce inequality by blaming parents and removing more children into the welfare system. If our aim is to prevent harms to children, then our primary focus should be on supporting, not forcing, women and their families through drug treatment and social services options.

\section{Acknowledgements}

Thank you to Jake Rance, Kari Lancaster, Kenneth Yates and Kev Dertadian for their comments and input into the first draft of this paper.

\section{References}

[1] Bromfield L, Holzer P, National Child Protection Clearinghouse. Australian Institute of Family Studies submission to the Special Commission of Inquiry into Child Protection Services in NSW. Melbourne: Australian Institute of Family Studies, 2008.

[2] O'Farrell B. Landmark child protection reforms to improve the lives of vulnerable children. 2013. Available at: http://www.nsw.gov.au/news/landmark-child-protection -reforms-improve-lives-vulnerable-children (accessed 25 September 2014).

[3] Valentine K, Treloar C. Response to Chandler et al., Substance, structure and stigma: parents in the UK accounting for opioid substitution therapy during the antenatal and postnatal periods. Int J Drug Policy 2013;24:e87-8.

[4] Atkinson J, Best D, Dawe S, Frye S, Moss D. Drug use in the family: impacts and implications for children (ANCD Research Paper No. 13). Technical working papers and reports ER. Canberra: Australian National Council on Drugs, 2006. 
[5] Leek L, Seneque D, Ward K. Parental drug and alcohol use as a contributing factor in applications to the Children's Court for protection orders. Child Aust 2009;34:11-16.

[6] NSW Human Services. Working with parental substance misuse. Sydney: NSW Government, 2010.

[7] Salmon A. Aboriginal mothering, FASD prevention and the contestations of neoliberal citizenship. In: Bell $\mathrm{K}$, McNaughton D, Salmon A, eds. Alcohol, tobacco and obesity: mortality and the new public health. Oxon: Routledge, 2011:212-25.

[8] Batagol R. Letter: changes in alcohol consumption in pregnant Australian women between 2007 and 2011. Med J Aust 2014;200:391-2.

[9] Lumley J, Chamberlain C, Dowswell T, Oliver S, Oakley L, Watson L. Interventions for promoting smoking cessation during pregnancy. Cochrane Database Syst Rev 2009; (3):CD001055.

[10] Harris B. Project Prevention. 2014. Available at: http:// www.projectprevention.org/ (accessed May 2014).

[11] Tuchman E. Women and addiction: the importance of gender issues in substance abuse research. J Addict Dis 2010;29:127-38.

[12] Moss K. Substance abuse during pregnancy. Harv Womens Law J 1990;13:278-99.

[13] Beckett K. Fetal rights and 'crack moms': pregnant women in the war on drugs. Contemp Drug Probl 1995;22:584612.

[14] Taylor A. Women drug users: an ethnography of a female injecting community. Oxford: Clarendon Press, 1993.

[15] Olsen A, Banwell C, Dance P, Maher L. Positive health beliefs and behaviours in the midst of difficult lives: women who inject drugs. Int J Drug Policy 2012;23:312-18.

[16] Taplin S, Mattick RP. The nature and extent of child protection involvement among heroin-using mothers in treatment: high rates of reports, removals at birth and children in care. Drug Alcohol Rev 2014; [Epub ahead of print].

[17] Radcliffe P. Substance-misusing women: stigma in the maternity setting. Br J Midwifery 2011;19:497-504.

[18] Powis B, Gossop M, Bury C, Payne K, Griffiths P. Drugusing mothers: social, psychological and substance use problems of women opiate users with children. Drug Alcohol Rev 2000;19:171-80.

[19] Taplin S, Mattick RP. Child protection and mothers in substance abuse treatment. Sydney: National Drug and Alcohol Research Centre, University of New South Wales, 2011.
[20] Bell K, McNaughton D, Salmon A. Introduction. In: Bell $\mathrm{K}$, McNaughton D, Salmon A, eds. Alcohol, tobacco and obesity: morality, mortality and the new public health. Oxon: Routledge, 2011:1-16.

[21] World Health Organization. Guidelines for the identification and management of substance use and substance use disorders in pregnancy. Geneva: WHO, 2014.

[22] NSW Department of Health. National clinical guidelines for the management of drug use during pregnancy, birth and the early development years of the newborn. Sydney: Commonwealth of Australia, 2006.

[23] Legislative Council and the Legislative Assembly of New South Wales. Child Protection Legislation Amendment Bill 2014. Sydney: New South Wales Government, 2013.

[24] NSW Government. Budget 2014-15. 2014. Available at: http://www.budget.nsw.gov.au/2014-15/budget_papers/ budget_paper_3 (accessed August 2014).

[25] Longman C, Lintzeris N, Temple-Smith M, Gilchrist G. Methadone and buprenorphine prescribing patterns of Victorian general practitioners: their first 5 years after authorisation. Drug Alcohol Rev 2011;30:355-9.

[26] Holliday S, Magin P, Dunbabin J, et al. Waiting room ambience and provision of opioid substitution therapy in general practice. Med J Aust 2012;196:391-4.

[27] Dawe S, Harnett P. Reducing potential for child abuse among methadone-maintained parents: results from a randomized controlled trial. J Subst Abuse Treat 2007; 32:381-90.

[28] Hayes A, Higgins D. Complex family issues: collective awareness, common narratives and coordinated approaches to promoting resilience. In: Hayes A, Higgins D, eds. Families, policy and the law: selected essays on contemporary issues for Australia. Melbourne: Australian Institute of Family Studies, 2014:299-303.

[29] Community Legal Centres NSW. Changes to child protection laws in NSW: Issues paper. 2014. Available at: http://www.clcnsw.org.au/cb_pages/child_protection.php (accessed May 2014).

[30] Roberts SM, Pies C. Complex calculations: how drug use during pregnancy becomes a barrier to prenatal care. Matern Child Health J 2011;15:333-41.

[31] Letourneau N, Campbell MA, Woodland J, Colpitts J. Supporting mothers' engagement in a community-based methadone treatment program. Nurs Res Pract 2013; 2013:1-11. 